\title{
Changes of multiple cropping in Huang-Huai-Hai agricultural region, China
}

\author{
YAN Huimin ${ }^{1,2}$, LIU Fang ${ }^{1}$, NIU Zhongen ${ }^{1,2}$, GU Fengxue ${ }^{3}$, YANG Yanzhao ${ }^{1,2}$ \\ 1. Institute of Geographic Sciences and Natural Resources Research, CAS, Beijing 100101, China; \\ 2. University of Chinese Academy of Sciences, Beijing 100049, China; \\ 3. Institute of Environment and Sustainable Development in Agriculture, Chinese Academy of Agricultural \\ Sciences, Beijing 100081, China
}

\begin{abstract}
Multiple cropping index $(\mathrm{MCl})$ is the ratio of total sown area and cropland area in a region, which represents the regional time intensity of planting crops. Multiple cropping systems have effectively improved the utilization efficiency and production of cropland by increasing cropping frequency in one year. Meanwhile, it has also significantly altered biogeochemical cycles. Therefore, exploring the spatio-temporal dynamics of multiple cropping intensity is of great significance for ensuring food and ecological security. In this study, $\mathrm{MCl}$ of Huang-Huai-Hai agricultural region with intensive cropping practices was extracted based on a cropping intensity mapping algorithm using MODIS Enhanced Vegetation Index (EVI) time series at 500-m spatial resolution and 8-day time intervals. Then the physical characteristics and landscape pattern of $\mathrm{MCl}$ trends were analyzed from 2000-2012. Results showed that $\mathrm{MCl}$ in Huang-Huai-Hai agricultural region has increased from $152 \%$ to $156 \%$ in the 12 years. Topography is a primary factor in determining the spatial pattern dynamics of $\mathrm{MCl}$, which is more stable in hilly area than in plain area. An increase from $158 \%$ to $164 \%$ of $\mathrm{MCl}$ occurred in plain area while there was almost no change in hilly area with single cropping. The most active region of $\mathrm{MCl}$ change was the intersection zone between the hilly area and plain area. In spatial patterns, landscape of multiple cropping systems tended to be homogenized reflected by a reduction in the degree of fragmentation and an increase in the degree of concentration of cropland with the same cropping system.
\end{abstract}

Keywords: Huang-Huai-Hai agricultural region; MCI; spatio-temporal dynamics; MODIS; EVI; landscape pattern

\section{Introduction}

Continued growth in population and food consumption has brought about the great challenge facing global agriculture to ensure a constant food supply while reducing negative environmental impacts (Robertson et al., 2005; Foley et al., 2005; 2011; Godfray et al., 2010; Tilman et al., 2011; Seufert et al., 2012). Cropland use intensity is not only an important characteristic of agricultural land use (Rudel, 2009), but also one of the major causes of envi-

Received: 2017-02-20 Accepted: 2017-09-15

Foundation: National Natural Science Foundation of China, No.41430861, No.41471453; Strategic Priority Research Program, the Chinese Academy of Sciences (CAS), No.XDA20010202

Author: Yan Huimin (1974-), PhD, specialized in land use change. E-mail: yanhm@igsnrr.ac.cn 
ronmental change (Foley et al., 2005). On one hand, improved cropland use intensity is one of the important and effective sources of growth in crop production. Seasonal farming produces complex and changeable mosaics at regional scale, which results in new landscape and ecological mechanisms. On the other hand, high agricultural land-use intensity has adjusted exchange rates of biogeochemical processes, altered biological diversity and affected energy flow and water cycling (Godfray et al., 2010; Tilman et al., 2011).

As for China, the largest food consumer, improving resource use efficiency by increasing cropland intensity is an essential pathway for ensuring food security (Shi et al., 2010). Multiple cropping is an effective way for increasing grain production (Liu et al., 2011; Zhang, 2011; Liang et al., 2012) by improving cropland use intensity at time dimension to increase the resource utilization efficiency and agricultural output (Bian et al., 1999). Multiple cropping land in China accounted for more than one-third of the total national cropland in 2002, and its spatial pattern changes with the dynamics of natural and socio-economic status (Qiu et al., 2003; Yan et al., 2005a; Yan et al., 2014). On one hand, potential for extending multiple cropping is investigated to increase agricultural output. On the other hand, multiple cropping rate decreases due to low efficiency of agriculture (Zhu et al., 2007; Jin et al., 2011; Liang et al., 2012; Song et al., 2012; Xu et al., 2013). However, current research reveals the large gaps in knowledge of spatial dynamics of multiple cropping intensity (MCI), which is an important determinant of sown area. Since grain production in China soared to its highest level ever in 1998, crop yield and total production have continually decreased, including a sharp decline in rice and wheat. So China began to face the grand challenge of achieving food security again. Grain output began to grow with increasing harvested areas in 2004, and through policy regulations, it exhibited a continued growth for the following ten years. The growth in the ten years may be due to the following reasons: increases in MCI (Zhang, 2011; Zhang et al., 2011a; Liang et al., 2012), large areas of cropland circulation, or reformation of mediumand low-yield cropland and construction of high-standard cropland (Zhao et al., 2009; Cheng, 2010; Zhang et al., 2011b; Yan et al., 2016). Therefore, it is of great importance to explore the spatio-temporal dynamics of multiple cropping intensity for understanding the impacts of cropland use intensity on agricultural production and ecosystem functions.

Statistical methods based on census data are the primary methods to map MCI for administrative regions (Xie and Liu, 2015). However, it only represents the regional average cropping intensity and fails to provide inter-regional variations (Yan et al., 2014). Satellite remote sensing is the most effective technique to detect large-scale land cover change. Data from remote sensing images have provided critical supports for identifying and monitoring land use change, vegetation dynamics and key phonological transition dates (Defries et al., 2000; Friedl et al., 2002; Xiao et al., 2002a; 2002b; Liu et al., 2003). Ding et al. (2015, 2016) computed MCI of China using SPOT NDVI data and GIMMS NDVI, respectively. MODIS (Moderate Resolution Imaging Spectroradiometer) data has been freely available since 2000. MODIS data has higher spatial resolution than AVHRR and better spectral resolution than SPOT, and is widely applied for vegetation phenology monitoring and multi-cropping practices mapping (Peng et al., 2006; Zuo et al., 2009; Wang et al., 2010; Kalfas et al., 2011). Yan et al. (2014) and Zuo et al. (2014) investigated spatial pattern of multiple cropping practices of China using MODIS data in 2000 and 2005, respectively. The Enhanced Vegetation Index (EVI) time series curve generated from MODIS reflects crop phenological cycles through specific cyclical turning points (peaks and troughs), which has become the primary 
technique for extracting MCI (Zuo et al., 2009; Wang et al., 2010).

Huang-Huai-Hai agricultural region is an important agricultural region with high irrigated cropping intensity in China. Multiple cropped areas in this region accounted for $30.46 \%$ of that in China. Statistical data indicated that grain production in this region increased from 163.37 million tons in 2000 to 203.34 million tons in 2012, with an increment of 39.97 million tons accounting for about one-third of the national increment. Meanwhile, cropland area decreased from $3.47 \times 10^{7}$ ha in 1996 to $3.27 \times 10^{7}$ ha in 2008 , while harvested area increased from $5.07 \times 10^{7}$ ha to $5.13 \times 10^{7}$ ha. Qiu et al. (2017) evaluated the cropping intensity trends in the North China plain from 1982-2013. Additionally, Ding et al. (2016) analyzed the spatio-temporal variation in MCI in Northern China using GIMMS NDVI data. The current researches mainly focus on the spatio-temporal variation of cropping intensity but the physical characteristics and landscape pattern of the trends remain weak. The objectives of this study are: 1) to recognize the dynamics of MCI in Huang-Huai-Hai agricultural region during the first 10 years of the 21 st century based on the constructed crop time-series growth curves from MODIS 500 m-resolution 8-day composite products (MOD09A1); and 2) to characterize the physical characteristics and landscape pattern of MCI trends.

\section{Data and methods}

\subsection{Study area}

Huang-Huai-Hai agricultural region is located in northern China, extending from $112^{\circ}-121^{\circ} \mathrm{E}$ to $31^{\circ}-41^{\circ} \mathrm{N}$. Geographically, it comprises all of Beijing, Tianjin, and Shandong Province, most parts of Hebei and Henan provinces, and the northern part of Jiangsu and Anhui provinces. As a typical alluvial plain based on the deposits of the Yellow River, Huaihe River, and Haihe River, the region is characterized by deep soil layers and soil texture suitable for farming (Liu and Long, 2016). The region has a temperate monsoon climate with semi-arid in the north and semi-humid in the south. The mean annual precipitation ranges from 280 to $1050 \mathrm{~mm}$ and the average temperature is $11^{\circ} \mathrm{C}$ to $15^{\circ} \mathrm{C}$, with the accumulated temperature $\geq 10^{\circ} \mathrm{C}$ ranging from $3800^{\circ} \mathrm{C}$ to $4900^{\circ} \mathrm{C}$ (Huang et al., 2016). The region is dominated by double-cropping systems with winter wheat-rice rotation in Jiangsu and Anhui provinces, and winter wheat-summer maize rotation in the other provinces and municipalities (Tao et al., 2017).

According to cropping system zones of China (Liu, 1993), the study area includes the following five sub-regions (Figure 1 and Table 1) with different geomorphic and water conditions (Fan, 2003; Yan, 2007): 1) Piedmonts of Taihang and Yanshan Mountains with irrigated double cropping and single cropping dry land; 2) Heilonggang lower-lying plain with irrigated double cropping and single cropping dry land; 3) Low plain in northwest Shandong and north Henan with irrigated grain double cropping and cotton single cropping land; 4) Shandong hilly region with irrigated double cropping and peanut-cotton single cropping sloping dryland; 5) Nanyang basin of the Huang-Huai Plain with dryland and irrigated double-crop.

\subsection{Data}

Spatial and areal information of cropland in Huang-Huai-Hai agricultural region was from 


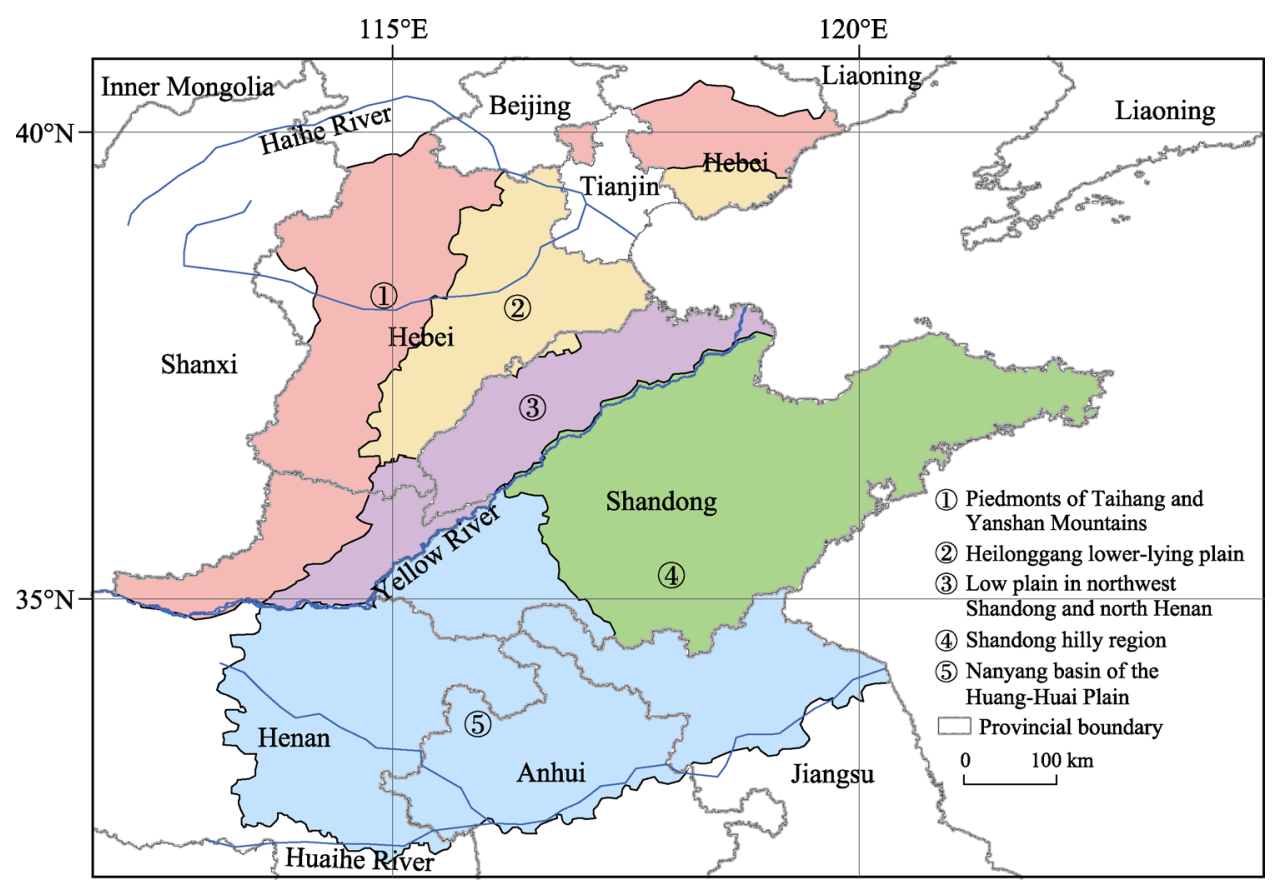

Figure 1 Location and sub-regions of Huang-Huai-Hai agricultural region

Table 1 Physical conditions of sub-regions in Huang-Huai-Hai agricultural region

\begin{tabular}{lcccccc}
\hline \multicolumn{1}{c}{ Sub-region } & $\begin{array}{c}\text { Area of } \\
\text { cropland } \\
\left(\times 10^{4} \mathrm{ha}\right)\end{array}$ & $\begin{array}{c}\text { Proportion } \\
\text { of crop- } \\
\text { land }(\%)\end{array}$ & $\begin{array}{c}\text { Mean annual } \\
\text { precipitation } \\
(\mathrm{mm})\end{array}$ & $\begin{array}{c}\geqslant 10^{\circ} \mathrm{C} \\
\text { accumulated } \\
\text { temperature } \\
\left({ }^{\circ} \mathrm{C}\right)\end{array}$ & $\begin{array}{c}\text { Proportion } \\
\text { of plain } \\
\text { area }(\%)\end{array}$ & $\begin{array}{c}\text { Propor- } \\
\text { tion of } \\
\text { hilly area } \\
(\%)\end{array}$ \\
\hline $\begin{array}{l}\text { Piedmonts of Taihang } \\
\text { and Yanshan Mountains }\end{array}$ & 535.61 & 15.13 & $600-900$ & $3500-4900$ & 66.69 & 33.31 \\
$\begin{array}{l}\text { Heilonggang lower-lying } \\
\text { plain }\end{array}$ & 462.36 & 13.06 & $600-750$ & $3400-4500$ & 99.96 & 0.04 \\
$\begin{array}{l}\text { Low plain in northwest } \\
\text { Shandong and north Henan }\end{array}$ & 387.20 & 10.94 & $700-900$ & $2600-4800$ & 99.68 & 0.32 \\
$\begin{array}{l}\text { Shandong hilly region } \\
\begin{array}{l}\text { Nanyang basin of the } \\
\text { Huang-Huai Plain }\end{array}\end{array}$ & 749.54 & 21.17 & $800-850$ & $3500-4200$ & 45.66 & 54.34 \\
\hline
\end{tabular}

the China's National Land-Use/Cover Dataset (NLCD) in 2000. NLCD data was derived through visual interpretation using Landsat TM/ETM+ images and validated through extensive field survey datasets (Liu et al., 2014). The area fraction cropland in each 1-km grid cell was calculated based on the vector maps. The $1-\mathrm{km}$ grid cells dominated by cropland were assigned as cropland, and were then resampled to $500 \mathrm{~m} \times 500 \mathrm{~m}$ for spatial consistency with cropping intensity result.

MODIS EVI datasets (Huete et al., 2002) in 2000 and 2012 used in this study were derived from 8-day MODIS surface reflectance product at $500 \mathrm{~m}$ from the MOD09A1 product (http://www.edc.usgs.gov/). EVI is calculated using the following equation:

$$
E V I=2.5 \times \frac{\rho_{\text {nir }}-\rho_{\text {red }}}{\rho_{\text {nir }}+6 \times \rho_{\text {red }}-7.5 \times \rho_{\text {blue }}+1}
$$

where $\rho_{\text {nir }}, \rho_{\text {red }}$ and $\rho_{\text {blue }}$ are the values of reflectance of NIR1, red and blue bands, respectively. 


\subsection{Multiple cropping index from MODIS EVI time series}

Vegetation index such as EVI is a directly remote sensing indicator for crop growth monitoring. An annual time series of EVI data covering 46 time phases reflects crop phonological stages including planting, emergence, heading, maturity and harvest (Jakubauskas et al., 2002; Sakamoto et al., 2007). The dynamic process of rise-peak-fall in EVI time series corresponds to a crop growth cycle. Therefore, the number of peaks in EVI time series in individual grid cell is regarded as the MCI of cropland. Generally, external influences, e.g., sun angles, clouds, atmosphere and soil, cause the abnormal fluctuation of EVI dataset (Gutman, 1991; Yan et al., 2005b). Therefore, Harmonic Analysis of Time Series (HANTS) method was applied in our study to remove these noises and reconstruct smooth and gapless EVI time series data. Based on harmonic analysis, the HANTS program has been proved an effective method for phenological studies (De Jong et al., 2011; Zhou et al., 2015), which uses Fourier transformation and the least square curve fitting method for reconstruction the smooth EVI time series. Crop phenological information provided by agro-meteorological observations was also involved to compute MCI using the peak value detection method (Yan, 2007). MCI is calculated using the following equation:

$$
\mathrm{MCI}=\frac{A_{1}}{A_{2}}
$$

where MCI refers to the multiple cropping index of cropland; $A_{1}$ represents total area harvested in a single year; $A_{2}$ represents total cropland area.

\subsection{Landscape metrics calculation}

Landscape fragmentation index (LFI) and patch density (PD) were chosen to measure the fragmentation of cropping pattern at regional and landscape scales, respectively. LFI refers to the ratio of the total number of patches to the total landscape area. PD is the ratio of patch number to the total patch type area. Lower LFI and PD values mean less fragmentation, suggesting that the landscape is composed of few large patches. Higher LFI and PD values indicate more fragmentation, that is, the landscape is composed largely of small patches (Wang et al., 1996; Li et al., 2011; Cheng et al., 2005).

$$
L F I=\frac{N}{S}
$$

where $N$ refers to the total number of patches; $S$ refers to the total landscape area.

$$
P D=\frac{N_{i}}{S_{i}}
$$

where $N_{i}$ represents the patch numbers of landscape $i$; $S_{i}$ represents the area of landscape $i$.

\section{Results}

\subsection{Changes in intensity of multiple cropping and its regional differences}

From 2000-2012, the area proportions of single- and triple-cropping croplands in Huang-Huai-Hai agricultural region dropped from $47.2 \%$ and $0.3 \%$ to $42.1 \%$ and $0.2 \%$, respectively, while the proportion of double-cropping area rose from $52.5 \%$ to $57.7 \%$. The 
average MCI increased from $152.67 \%$ to $156.67 \%$ was mainly attributed to expansion of double-cropped areas. In space, about $25 \%$ and $16 \%$ of cropland area suffered an increase and decrease in MCI, respectively. Among the five sub-regions, decreased MCI primarily occurred in piedmonts of Taihang and Yanshan Mountains (region (1), Table 2). In this region, single-cropped area increased from $306 \times 10^{4}$ ha to $320 \times 10^{4}$ ha and double-cropped area decreased from $227 \times 10^{4}$ ha to $209 \times 10^{4}$ ha. There was $24.54 \%$ of cropland with multiple cropping intensity declined and $15.95 \%$ of cropland rose at the same time. MCI increased primarily in Low plain in northwest Shandong and north Henan (region (3) and Nanyang basin of the Huang-Huai Plain (region (5) with high cropping intensity. In these two regions, average MCI increased from $165.47 \%$ and $177.97 \%$ to $173.57 \%$ and $188.89 \%$, respectively. Multiple cropped areas increased in both regions, with the proportions of multiple cropping land reached about $73 \%$ and $90 \%$, respectively. Shandong hilly region (region (4)) and Heilonggang lower-lying plain (region (2) have relatively stable MCI (Table 2). Region (4) experienced a slight decline in single-crop land from $545 \times 10^{4}$ ha to $535 \times 10^{4}$ ha, as well as a slight expansion in double-crop land from $200 \times 10^{4}$ ha to $204 \times 10^{4}$ ha. In region (2), cropland with single-cropping system increased from $353 \times 10^{4}$ ha to $355 \times 10^{4}$ ha while double-cropping area decreased from $106 \times 10^{4}$ ha to $104 \times 10^{4}$ ha. Similar proportions of croplands suffered the increased and decreased cropping index in both regions.

Table 2 MCI changes and the corresponding croplands proportions in sub-regions in Huang-Huai-Hai agricultural region during 2000-2012

\begin{tabular}{|c|c|c|c|c|c|c|}
\hline \multirow[b]{2}{*}{ Sub-region } & \multicolumn{3}{|c|}{ Average MCI (\%) } & \multicolumn{3}{|c|}{ Proportion of cropland (\%) } \\
\hline & 2000 & 2012 & Change & $\begin{array}{c}\text { Increased } \\
\text { MCI }\end{array}$ & $\begin{array}{c}\text { Decreased } \\
\text { MCI }\end{array}$ & $\begin{array}{l}\text { Stable } \\
\text { MCI }\end{array}$ \\
\hline $\begin{array}{l}\text { Piedmonts of Taihang and } \\
\text { Yanshan Mountains }\end{array}$ & 142.07 & 137.27 & -4.8 & 15.95 & 24.54 & 59.52 \\
\hline Heilonggang lower-lying plain & 122.29 & 121.37 & -0.92 & 16.92 & 21.71 & 61.37 \\
\hline $\begin{array}{l}\text { Low plain in northwest Shan- } \\
\text { dong and north Henan }\end{array}$ & 165.47 & 173.57 & 8.1 & 29.41 & 12.42 & 58.18 \\
\hline Shandong hilly region & 126.52 & 126.22 & -0.3 & 18.43 & 19.82 & 61.74 \\
\hline $\begin{array}{l}\text { Nanyang basin of the } \\
\text { Huang-Huai Plain }\end{array}$ & 177.97 & 188.89 & 10.92 & 33.57 & 9.91 & 56.52 \\
\hline
\end{tabular}

\subsection{Physical characteristics in the stable or variant regions of multiple cropping change}

Topography and hydrothermal conditions are the major potential reasons for trend differences of MCI in different regions. Relief degree of land surface is an important regional topographic index in describing macroscopic landform, which can be represented as maximum height difference in a certain distance. Generally, the regions with a relief degree lower than $30 \mathrm{~m}$ are defined as plain area and regions with a relief degree higher than $30 \mathrm{~m}$ are defined as hilly area (Liu et al., 2001; Yan et al., 2016).

In Huang-Huai-Hai agricultural region, MCI in hilly area was more stable than that in plain area (Figure 2). From 2000 to 2012, the average MCI of cropland in plain area increased from $158 \%$ to $164 \%$, while that in hilly area remained stable. The cropland area proportions with increased, stable and decreased MCI in plain area were about $27.43 \%$, $56.04 \%$, and $16.53 \%$ while the corresponding area proportions in hilly area were $16.46 \%$, 
$68.80 \%$ and $14.74 \%$ (Figure 2). According to piedmonts of Taihang and Yanshan Mountains (1) and Shandong hilly region (4) with a large proportion of hilly area (Table 1), croplands with stable cropping intensity in hilly areas were 20.05 and 29.63 points higher than that in plain area (Figure 2). Graphically, $65.19 \%$ of cropland with increased MCI was distributed in plain-dominated regions such as low plain in northwest Shandong and north Henan (3) and Nanyang basin of the Huang-Huai Plain (5)). 49.69\% of cropland with decreasing MCI was located in regions (1) and (4) (Table 3). The regional average MCI of cropland in both plain and hilly areas increased in regions (3) and (5) (Table 4).

(a) $\square$ Decreased MCI $\square$ Stable MCI $\mathrm{G}$ Increased MCI

(b) $\square$ Decreased MCI $\circledast$ Stable MCI $\mathrm{Q}$ Increased MCI
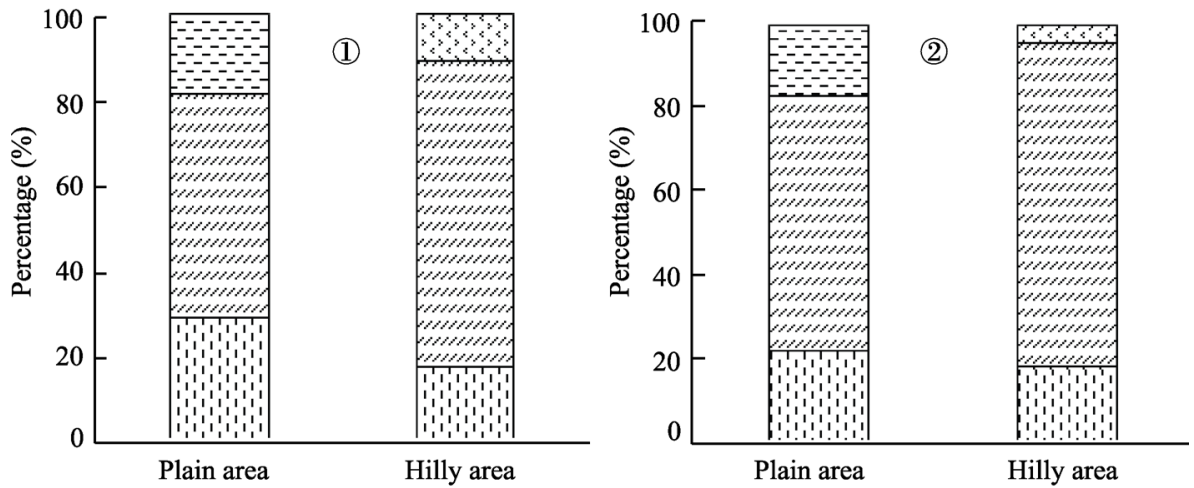

(c) $\square$ Decreased MCI $\square$ Stable MCI $\square$ Increased MCI

(d)
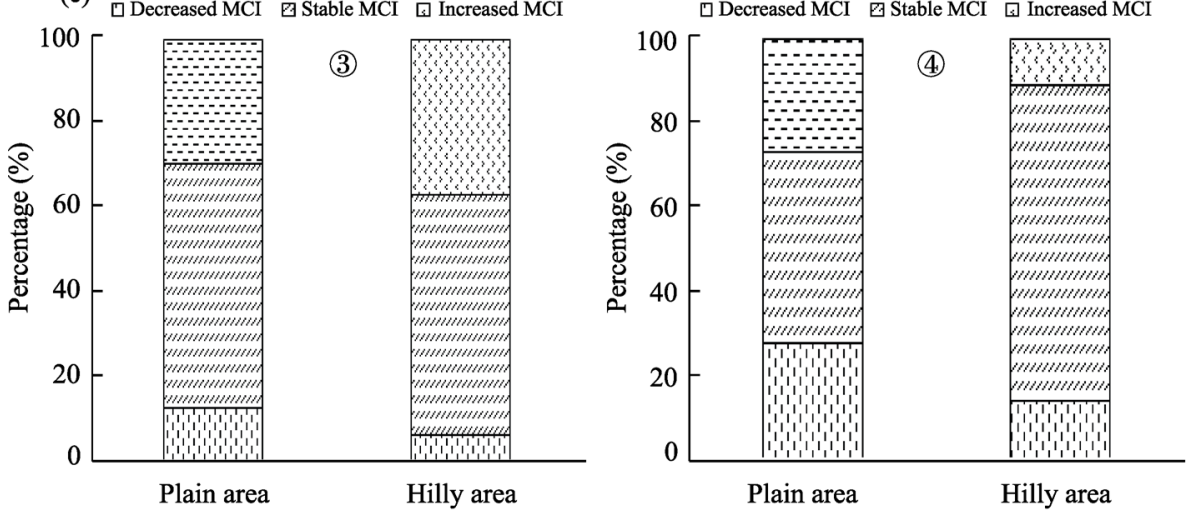

(e) $\square$ Decreased MCI $\square$ Stable MCI $\square$ Increased MCI
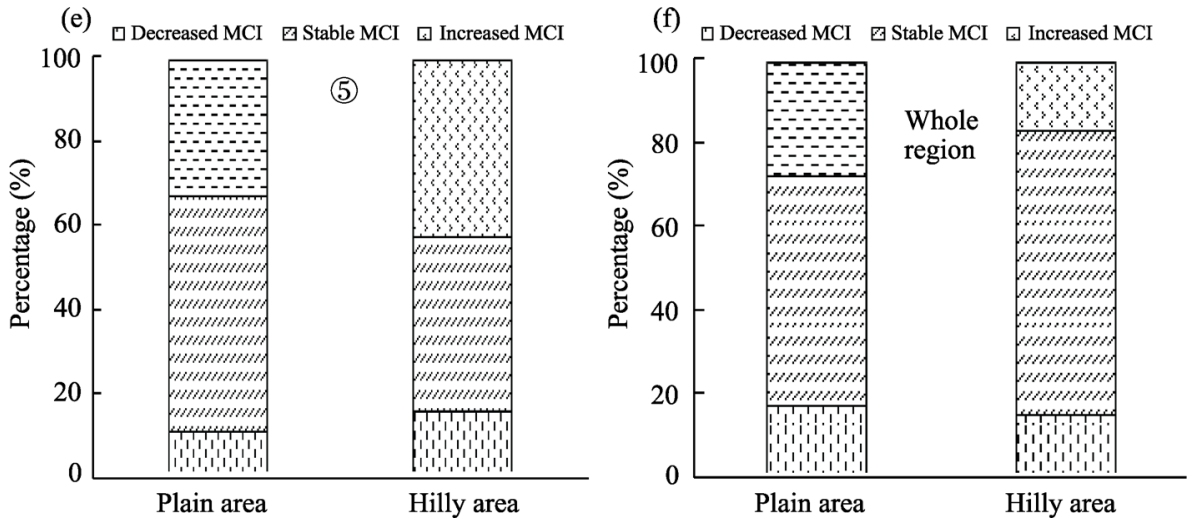

Figure 2 MCI changes in plain area and hilly area of sub-regions and the whole region during 2000-2012 
Table 3 Proportions of cropland with increased and decreased MCI in each sub-region in Huang-Huai-Hai agricultural region during 2000-2012 (\%)

\begin{tabular}{|c|c|c|c|c|c|c|}
\hline \multirow[b]{2}{*}{ Sub-region } & \multirow{2}{*}{$\begin{array}{c}\text { Proportion of } \\
\text { increased } \\
\text { MCI }\end{array}$} & & & \multirow{2}{*}{$\begin{array}{c}\text { Proportion of } \\
\text { decreased } \\
\text { MCI }\end{array}$} & \multirow[b]{2}{*}{$\begin{array}{c}\text { Plain } \\
\text { area }\end{array}$} & \multirow[b]{2}{*}{ Hilly area } \\
\hline & & $\begin{array}{c}\text { Plain } \\
\text { area }\end{array}$ & $\begin{array}{r}\text { Hilly } \\
\text { area }\end{array}$ & & & \\
\hline $\begin{array}{l}\text { Piedmonts of Taihang and } \\
\text { Yanshan Mountains }\end{array}$ & 9.96 & 79.16 & 20.84 & 23.63 & 78.32 & 21.68 \\
\hline $\begin{array}{l}\text { Heilonggang lower-lying } \\
\text { plain }\end{array}$ & 9.13 & 99.99 & 0.01 & 18.08 & 99.97 & 0.03 \\
\hline $\begin{array}{l}\text { Low plain in northwest } \\
\text { Shandong and north Henan }\end{array}$ & 13.00 & 99.65 & 0.35 & 8.47 & 99.85 & 0.15 \\
\hline Shandong hilly region & 15.71 & 66.78 & 33.22 & 26.06 & 63.52 & 36.48 \\
\hline $\begin{array}{l}\text { Nanyang basin of the } \\
\text { Huang-Huai Plain }\end{array}$ & 52.19 & 91.22 & 8.78 & 23.76 & 90.08 & 9.92 \\
\hline
\end{tabular}

Table 4 MCI changes in plain area and hilly area of sub-regions in Huang-Huai-Hai agricultural region during 2000-2012(\%)

\begin{tabular}{lcccccccc}
\hline \multirow{2}{*}{ Sub-region } & \multicolumn{3}{c}{ Plain area } & & \multicolumn{3}{c}{ Hilly area } \\
\cline { 2 - 3 } \cline { 7 - 9 } & 2000 & 2012 & Change & & 2000 & 2012 & Change \\
\hline Piedmonts of Taihang and Yanshan Mountains & 157.12 & 151.75 & -5.37 & & 116.15 & 112.50 & -3.65 \\
Heilonggang lower-lying plain & 122.59 & 121.79 & -0.80 & & 100.00 & 95.44 & -4.56 \\
Low plain in northwest Shandong and north Henan & 166.15 & 174.31 & 8.16 & & 178.41 & 190.72 & 12.31 \\
Shandong hilly region & 145.61 & 145.18 & -0.43 & & 111.76 & 111.77 & 0.02 \\
Nanyang basin of the Huang-Huai Plain & 180.47 & 191.13 & 10.66 & & 151.33 & 165.86 & 14.53 \\
\hline
\end{tabular}

Figure 3 shows that cropland with declining MCI in plain area was mostly located in the intersection zone of hills and plains. Cropland with increasing MCI in hilly area was also distributed in boundary zone of hilly and plain area. The MCI of cropland was almost stable in the plain hinterland and the core part of hilly area. Buffer zones of 10, 20 and $30 \mathrm{~km}$ around hilly area were identified as piedmont plain area, and the rest of the plain was identified as plain area. Results showed that hilly area had the largest proportion of cropland with stable MCI, followed by plain area and then piedmont plain area. The piedmont plain area had a similar proportion of cropland with increasing cropping intensity to the plain area, as well as a larger proportion of cropland with declining cropping intensity than both hilly area and plain area. It seemed that MCI of cropland in plain area and hilly area was relatively stable and that in piedmont plain area was prone to change (Table 5).

Table 5 Proportions of cropland with increased and decreased MCI of plain area, piedmont plain area and hilly area in Huang-Huai-Hai agricultural region during 2000-2012 (\%)

\begin{tabular}{|c|c|c|c|c|c|c|c|c|c|}
\hline \multirow{2}{*}{$\begin{array}{l}\text { Buffer } \\
\text { zones }\end{array}$} & \multicolumn{3}{|c|}{ Plain area } & \multicolumn{3}{|c|}{ Piedmont plain area } & \multicolumn{3}{|c|}{ Hilly area } \\
\hline & $\begin{array}{c}\text { Decreased } \\
\mathrm{MCI}\end{array}$ & $\begin{array}{c}\text { Stable } \\
\text { MCI }\end{array}$ & $\begin{array}{c}\text { Increased } \\
\text { MCI }\end{array}$ & $\begin{array}{c}\text { Decreased } \\
\text { MCI }\end{array}$ & $\begin{array}{c}\text { Stable } \\
\text { MCI }\end{array}$ & $\begin{array}{c}\text { Increased } \\
\text { MCI }\end{array}$ & $\begin{array}{c}\text { Decreased } \\
\mathrm{MCI}\end{array}$ & $\begin{array}{c}\text { Stable } \\
\text { MCI }\end{array}$ & $\begin{array}{c}\text { Increased } \\
\text { MCI }\end{array}$ \\
\hline $10 \mathrm{~km}$ & 15.39 & 57.47 & 27.15 & 20.23 & 52.56 & 27.21 & 14.74 & 68.80 & 16.46 \\
\hline $20 \mathrm{~km}$ & 14.85 & 58.72 & 26.43 & 19.46 & 52.26 & 28.27 & 14.74 & 68.80 & 16.46 \\
\hline $30 \mathrm{~km}$ & 14.56 & 59.53 & 25.91 & 18.79 & 52.77 & 28.44 & 14.74 & 68.80 & 16.46 \\
\hline
\end{tabular}

Hydrothermal conditions also affected the spatial pattern of MCI changes. The MCI decreased croplands were mainly distributed in Heilonggang lower-lying plain (2) characterized by low precipitation and groundwater level restricting irrigation agriculture (Figure 3 ). 
Cropland with decreased MCI in this region accounted for $18.08 \%$ of that in Huang-HuaiHai agricultural region. In terms of Low plain in northwest Shandong and north Henan (3) with flat terrain and abundant water resources, MCI in plain area increased from $166.15 \%$ to $174.31 \%$. According to Nanyang basin of the Huang-Huai Plain (5) with favorable hydrothermal conditions, MCI in plain area rose from $180.47 \%$ to $191.13 \%$. Good hydrothermal conditions favored a rise in cropping intensity in hilly area in these two regions from $178.41 \%$ and $190.72 \%$ to $151.33 \%$ and $165.86 \%$, respectively. Owing to little limitations to multiple cropping practices in regions (3) and (5), cropland with increasing MCI in these regions accounted for $13.00 \%$ and $52.19 \%$ of that in Huang-Huai-Hai agricultural region, respectively (Table 3).

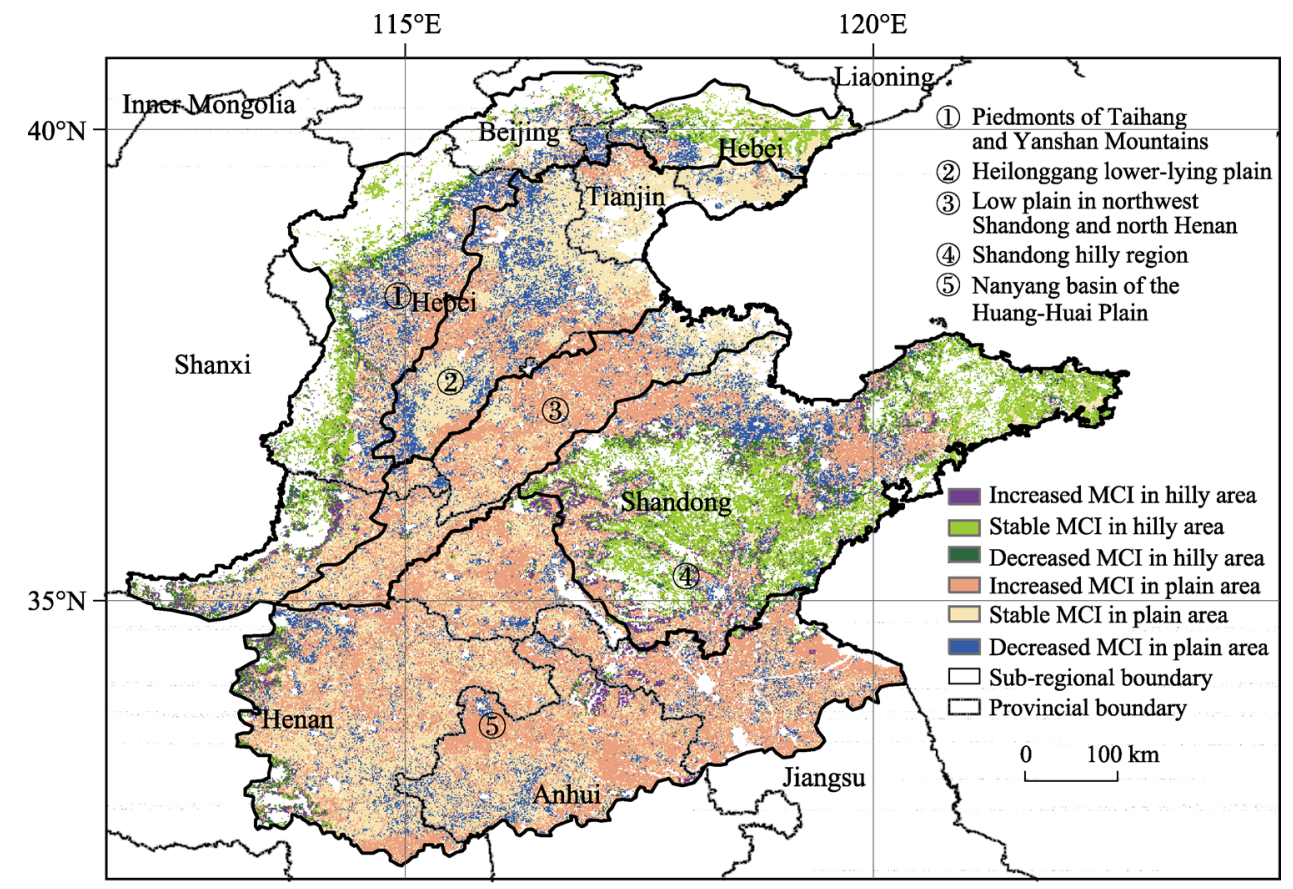

Figure 3 Multiple cropping dynamics with various topographic conditions in Huang-Huai-Hai agricultural region during 2000-2012

\subsection{Changes in landscape patterns of multiple cropping}

Landscape index including landscape fragmentation index (LFI) and patch density index (PD) were calculated to analyze the spatial pattern characteristics of multi-cropped land and non-multi-cropped land from 2000-2012. The MCI of single-cropping land was less than or equal to $100 \%$. MCI of double-cropping land reached values between $100 \%$ and $200 \%$. The triple-cropping land usually had MCI more than 200\% (Figure 4). The single-, double-and triple-cropping croplands were regarded as three types of landscape.

Results showed that fragmentation degree decreased at both regional and landscape scales from 2000 to 2012 (Table 6). Landscape fragmentation index declined by 50\%. Patch density of double- and single-cropping land decreased by $50 \%$ and $40 \%$, respectively. Triple-cropping land had a minimum reduction in cropland patch density $(5 \%)$. The decreased fragmentation degree of croplands with various cropping systems in Huang-Huai-Hai agricultural 



Figure 4 Spatial distribution map of multiple cropping systems in Huang-Huai-Hai agricultural region in 2000 (a) and 2012 (b)

Table 6 Patch density and landscape fragmentation index in Huang-Huai-Hai agricultural region in 2000 and 2012

\begin{tabular}{|c|c|c|c|c|}
\hline \multirow{2}{*}{ Landscape types } & \multicolumn{2}{|c|}{2000} & \multicolumn{2}{|c|}{2012} \\
\hline & $\mathrm{PD}$ & LFI & PD & LFI \\
\hline Single-cropping land & 0.20 & & 0.12 & \\
\hline Double-cropping land & 0.08 & 0.16 & 0.04 & 0.08 \\
\hline Triple-cropping land & 2.96 & & 2.80 & \\
\hline
\end{tabular}

region indicated that croplands with the same cropping systems tended to be spatially aggregately distributed. For example, in the central part of Heilonggang lower-lying plain (2), single- and double-cropping land was largely crossly distributed in 2000 (Figure 4). When it came to 2012, a clearer boundary between single- and double-cropping land was identified, that is, the former was concentrated in the northeast and southwest parts, and the latter was mainly located in southwest of central region. In Nanyang basin of the Huang-Huai Plain (5), the scattered and dispersed distribution pattern of single- and triple-cropping land turned to concentratedly distributed around the west boundary of regions (3) and (5), which led to the higher connectivity of double-cropping landscape.

\section{Conclusions and discussion}

\subsection{Conclusions}

Monitoring MCI dynamics is of great importance for estimating future agricultural produc- 
tion and achieving food security. Compared with the traditional statistical methods, monitoring $\mathrm{MCI}$ is faster and more effective based on time-series vegetation index, and can represent the detailed information of spatio-temporal patterns of cropping intensity. In this paper, the 8-day interval MODIS EVI data with a spatial resolution of $500 \mathrm{~m}$ was applied to identify multiple cropping changes in Huang-Huai-Hai agricultural region from 2000 to 2012.

The area proportion of single-cropping land declined from $47.2 \%$ to $42.1 \%$ and the area proportion of double-cropping land increased from $52.5 \%$ to $57.7 \%$ in Huang-Huai-Hai agricultural region. Regional MCI increased from $152.67 \%$ to $156.67 \%$ with significant regional variations. MCI increased in $25 \%$ of cropland and dropped in $16 \%$ of cropland.

Terrain is an important factor affecting spatial pattern of MCI changes. MCI in hilly area was more stable than that in plain area. The average MCI of cropland in plain area increased from $158 \%$ to $164 \%$, while that in hilly area remained stable. Some $65.19 \%$ of the cropland with increasing cropping index primarily occurred in the low plain in northwest Shandong and north Henan (3) and Nanyang basin of the Huang-Huai Plain (5) where plain cropland was dominated. $49.69 \%$ of cropland with decreasing MCI was located in regions (1) and (4) with a large proportion of hilly area. The intersection zone of hills and plains was more prone to cropping system change. The area proportion of cropland with stable MCI decreased in the order of the piedmont plain area, plain area and hilly area. There was similar area proportion of cropland with increasing MCI in the piedmont plain area and plain area. However, cropland with decreasing $\mathrm{MCI}$ in the piedmont plain area was more than that in hilly area and plain area. The piedmont plain area and bordering area of hilly area and plain area were prone to a decline and rise in MCI, respectively. Cropping intensity of the cropland in core area between hilly area and plain area was relatively stable.

Hydrothermal condition is another important factor influencing the dynamics trend of MCI. Decreased MCI tended to occur in the region with scarce precipitation and underwater resources. Heilonggang lower-lying plain (2) suffered declined MCI because costly irrigation forced farmers to give up growing crops (Zhang et al., 2014). 18.08\% of the cropland with decreasing cropping intensity in Huang-Huai-Hai agricultural region was distributed in this region. In the low plain in northwest Shandong and north Henan (3) and Nanyang basin of the Huang-Huai Plain (5) with favorable hydrothermal conditions and double cropping system, MCI rose from $151.33 \%$ and $178.41 \%$ to $165.86 \%$ and $190.72 \%$, respectively.

Changes in multiple cropping in Huang-Huai-Hai agricultural region was not only represented by MCI changes, but also embodied in significant variations of landscape pattern. According to landscape dynamics of multiple cropping system based on LFI and PD, multiple cropping intensity in this region represented a more uniform trend. The spatial fragmentation degree of multiple cropping cropland decreased, and croplands with the same cropping system tended to be aggregatively distributed, which meant agricultural technology and large-scale farming might be another important reasons for promoting multiple cropping systems change.

\subsection{Discussion}

The urbanization, agricultural policies and technological advancements have huge influences 
on the farmers' enthusiasm and farming practices. The conflict between achieving national food security and farmers seeking to maximize economic benefits is the direct cause of multiple cropping intensity change. The implementations of China's agricultural support policies have effectively stimulated farmers' enthusiasm for grain production and slowed down or even reversed the decreased tendency of MCI; the minimum grain purchasing price policies have ensured farmers' stable income and balanced goals at both national and farm household scales (Zhu et al., 2007; Xu et al., 2013; Liang et al., 2012; Song et al., 2012). Although more farmers are going out as migrant workers due to more employment opportunities resulting from urbanization (Chen et al., 2009; Chen et al., 2014), farmers' enthusiasm has been significantly encouraged by national policies related grain production, leading to a rise in multiple cropping intensity in Huang-Huai-Hai agricultural region. Regional variations in MCI indicate the constraints of natural environment on policy feasibility. So the development and application of policies should take full account of the timeliness, socio-economic development and natural endowments of different regions (Huang, 2004; Zhu et al., 2007; Song et al., 2012). For example, land resources in the piedmont plain area might face the conversion of agricultural land to nonagricultural uses (Wu et al., 2001). In China, farmland fragmentation due to agricultural land allocation system is an essential limitation to large-scale farming which will promote agricultural mechanization development, facilitate agricultural labor liberation and further increase the cropping intensity (Tan et al., 2006; Liang, 2007). With the implementation of large-scale agricultural mechanization, reasonable and orderly land circulation has been carried out to promote large-scale agricultural mechanization production, develop modern agriculture, make the best use of land resource, realize liberation of agricultural labor to the greatest extent and raise farmers' income on the premise of food security. However, intensive farming practices will have profound effects on the biogeochemical cycles. High intensity irrigation in agriculture has led to rapid decline in water table and surface subsidence over half the area in Huang-Huai-Hai agricultural region (Zhang et al., 2014; Xu, 2003). Therefore, it becomes a pressing issue for decision makers to create rational policies to ensure grain production without compromising environmental sustainability.

The limitations of MCI trends analysis could come from the cloud cover and low spatial resolution of MODIS data (Jain et al., 2013; Qiu et al., 2017). First, the continuous cloud-free MODIS images for the whole region are unavailable. Qiu et al. (2017) demonstrated the cloud cover ratio of MODIS data showed spatio-temporal variations in Huang-Huai-Hai region from 2001-2013. As the cloud-free images, SAR satellite images are promising choices for higher accuracy of cropping intensity monitoring. Second, some farm plots in the study area are smaller than the size of single MODIS pixel. The heterogeneity of land covers in one pixel will lead to heterogeneous cropping intensity. Therefore, higher spatial resolutions of satellite data are required for more accurate results for smallholder fields. Correspondingly, for our further work, we will combine Landsat TM/ETM+, Landsat 8 OLI and Sentinel-1/2 for improving the cropping intensity monitoring at both spatial and temporal resolutions.

\section{References}

Bian X M, Feng J X, 1999. Method of calculating cropping system index of diversified multiple cropping systems. 
Journal of Nanjing Agricultural University, 22(1): 11-15. (in Chinese)

Chen M Q, Zhong T Y, Wu Y H, 2014. Effect of agricultural subsidy policy on farmers' behavior to protect cultivated land. Journal of Agro-Forestry Economics and Management, 13(1): 14-23. (in Chinese)

Chen Y Q, Li X B, Tian Y J et al., 2009. Structural change of agricultural land use intensity and its regional disparity in China. Journal of Geographical Sciences, 19(5): 545-556.

Cheng J, Wu Z F, Liu P, 2005. Study on the change of agriculture landscape pattern based on GIS: A case study from Mapping Town, Zhangpu County. Chinese Journal of Eco-Agriculture, 13(4): 184-186. (in Chinese)

Cheng Y Q, 2010. Regional modes and countermeasure on the improvement of medium-low productivity farmland in northeastern China. Journal of Arid Land Resources \& Environment, 24(11): 120-124. (in Chinese)

De Jong R, de Bruin S, de Wit A et al., 2011. Analysis of monotonic greening and browning trends from global NDVI time-series. Remote Sensing Environment, 115(2): 692-702.

DeFries R S, Hansen M C, Townshend J R G, 2000. Global continuous fields of vegetation characteristics: A linear mixture model applied to multi-year $8 \mathrm{~km}$ AVHRR data. International Journal of Remote Sensing, 21(6/7): 1389-1414.

Ding M J, Chen Q, Xi L et al., 2015. Spatial and temporal variations of multiple cropping index in China based on SPOT-NDVI during 1999-2013. Acta Geographica Sinica, 70(7): 1080-1090. (in Chinese)

Ding M J, Chen Q, Xiao X M et al., 2016. Variation in cropping intensity in northern China from 1982 to 2012 based on GIMMS-NDVI data. Sustainability, 8(11): 1123.

Fan J L, 2003. Study on remote sensing methods for monitoring multiple cropping index [D]. Beijing: Chinese Academy of Science. (in Chinese)

Foley J A, DeFries R, Asner G P et al., 2005. Global consequences of land use. Science, 309(5734): 570-574.

Foley J A, Ramankutty N, Brauman K A et al., 2011. Solutions for a cultivated planet. Nature, 478 (7369): 337-342.

Friedl M A, McIver D K, Hodges J C F et al., 2002. Global land cover mapping from MODIS: Algorithms and early results. Remote Sensing of Environment, 83(1/2): 287-302.

Godfray H C J, Beddington J R, Crute I R et al., 2010. Food security: The challenge of feeding 9 billion people. Science, 327(5967): 812-818.

Gutman G G, 1991. Vegetation indices from AVHRR: An update and future prospects. Remote Sensing of Environment, 35(2/3): 121-136.

Huang J K, 2004. Past and future of the agriculture in China. Management World, (3): 95-104. (in Chinese)

Huang Q, Wang L M, Chen Z X et al., 2016. Effects of meteorological factors on different grades of winter wheat growth in the Huang-Huai-Hai Plain, China. Journal of Integrative Agriculture, 15(11): 2647-2657.

Huete A, Didan K, Miura T et al., 2002. Overview of the radiometric and biophysical performance of the MODIS vegetation indices. Remote Sensing of Environment, 83(1/2): 195-213.

Jain M, Mondal P, DeFries R S et al., 2013. Mapping cropping intensity of smallholder farms: A comparison of methods using multiple sensors. Remote Sensing of Environment, 134: 210-223.

Jakubauskas M E, Legates D R, Kastens J H, 2002. Crop identification using harmonic analysis of time-series AVHRR NDVI data. Computers \& Electronics in Agriculture, 37(1-3): 127-139.

Jin S L, Hou L C, Xu L, 2011. The relationship of multiple cropping index of arable land change and national food security in the middle and lower reaches of Yangtze River. Chinese Agricultural Science Bulletin, 27(17): 208-212. (in Chinese)

Kalfas J L, Xiao X M, Vanegas D X et al., 2011. Modeling gross primary production of irrigated and rain-fed maize using MODIS imagery and $\mathrm{CO}_{2}$ flux tower data. Agricultural \& Forest Meteorology, 151(12): 1514-1528.

Li T, Lai H, Zhang S R, 2011. Dynamics analysis of land use and landscape pattern change in Yuechi County. Geospatial Information, 9(4): 111-114. (in Chinese)

Liang S M, 2007. Probing potentials of multiple cropping in the selected provinces in China. Issues in Agricultural Economy, 28(5): 85-90. (in Chinese)

Liang S Z, Ma W D, Shi P et al., 2012. Monitoring multiple cropping index using MODIS NDVI data. Chinese 
Journal of Eco-Agriculture, 20(12): 1657-1663. (in Chinese)

Liu J Y, Kuang W H, Zhang Z X, et al.,2014. Spatiotemporal characteristics, patterns, and causes of land-use changes in China since the late 1980s. Journal of Geographical Sciences, 24(2): 195-210.

Liu J Y, Zhuang D F, Luo D et al., 2003. Land-cover classification of China: Integrated analysis of AVHRR imagery and geophysical data. International Journal of Remote Sensing, 24(12): 2485-2500.

Liu X H, 1993. Chinese Cropping System. Beijing: Agriculture Press. (in Chinese)

Liu X H, Yang Q K, Tang G A, 2001. Extraction and application of relief of China based on DEM and GIS method. Bulletin of Soil \& Water Conservation, 21(1): 57-60. (in Chinese)

Liu Y, Liu Y S, Guo L Y, 2011. Evolvement of spatial pattern of per capita grain possession at county level in the area along Bohai Rim of China. Scientia Geographica Sinica, 31(1): 102-109. (in Chinese)

Liu Y Q, Long H L, 2016. Land use transitions and their dynamics mechanism: The case of the Huang-Huai-Hai Plain. Journal of Geographical Sciences, 26(5): 515-530.

Peng D L, Huang J F, Jin H M, 2006. The monitoring for sequential cropping index of arable land in Zhejiang Province using MODIS-NDVI. Scientia Agricultura Sinica, 39(7): 1352-1357. (in Chinese)

Qiu B W, Lu D F, Tang Z H et al., 2017. Mapping cropping intensity trends in China during 1982-2013. Applied Geography, 79: 212-222.

Qiu J J, Tang H J, Frolking S et al., 2003. Mapping single-, double-, and triple-crop agriculture in China at $0.5^{\circ} \times 0.5^{\circ}$ by combining county-scale census data with a remote sensing-derived land cover map. Geocarto International, 18(2): 3-13.

Robertson G P, Swinton S M, 2005. Reconciling agricultural productivity and environmental integrity: A grand challenge for agriculture. Frontiers in Ecology \& the Environment, 3(1): 38-46.

Rudel T K, 2009. Tree farms: Driving forces and regional patterns in the global expansion of forest plantations. Land Use Policy, 26(3): 545-550.

Sakamoto T, Van Nguyen N, Kotera A et al., 2007. Detecting temporal changes in the extent of annual flooding within the Cambodia and the Vietnamese Mekong Delta from MODIS time-series imagery. Remote Sensing of Environment, 109(3): 295-313.

Seufert V, Ramankutty N, Foley J A, 2012. Comparing the yields of organic and conventional agriculture. Nature, 485(7397): 229-232.

Shi Q H, Wang H, Chen F et al., 2010. The spatial-temporal distribution characteristics and yield potential of medium-low yielded farmland in China. Chinese Agricultural Science Bulletin, 26(19): 369-373. (in Chinese)

Song X Q, Ouyang Z, 2012. Key influencing factors of food security guarantee in China during 1999-2007. Acta Geographica Sinica, 67(6): 793-803. (in Chinese)

Tan S, Heerink N, Qu F, 2006. Land fragmentation and its driving forces in China. Land Use Policy, 23(3): 272-285.

Tao F L, Xiao D P, Zhang S et al., 2017. Wheat yield benefited from increases in minimum temperature in the Huang-Huai-Hai Plain of China in the past three decades. Agricultural and Forest Meteorology, 239(28): $1-14$.

Tilman D, Balzer C, Hill J et al., 2011. Global food demand and the sustainable intensification of agriculture. Proceedings of the National Academy of Sciences of the United States of America, 108(50): 20260-20264.

Wang L H, Huang J L, Sun J Y, 2010. Monitoring for multiple cropping index of cultivated land in central China using time series of MODIS-EVI. Resources \& Environment in the Yangtze Basin, 19(5): 529-534. (in Chinese)

Wang X L, Bu R C, Hu Y M et al., 1996. Analysis on landscape fragment of Liaohe delta wetlands. Chinese Journal of Applied Ecology, 7(3): 299-304. (in Chinese)

Wu K, Huang R J, 2001. The sustainable evaluations, the development potentialities and the countermeasures of water and land resources use in the Huang-Huai-Hai Plain. Scientia Agricultura Sinica, 21(5): 390-395. (in Chinese)

Xiao X, Boles S, Frolking S et al., 2002a. Landscape-scale characterization of cropland in China using vegetation and Landsat TM images. International Journal of Remote Sensing, 23(18): 3579-3594. 
Xiao X, Boles S, Frolking S et al., 2002b. Observation of flooding and rice transplanting of paddy rice fields at the site to landscape scales in China using VEGETATION sensor data. International Journal of Remote Sensing, 23(15): 3009-3022.

Xie H L, Liu G Y, 2015. Spatiotemporal differences and influencing factors of multiple cropping index in China during 1998-2012. Journal of Geographical Sciences, 25(11): 1283-1297.

$\mathrm{Xu}$ X B, Yang G S, 2013. Spatial and temporal changes of multiple cropping index in 1995-2010 in Taihu Lake basin, China. Transactions of the Chinese Society of Agricultural Engineering, 29(3): 148-155. (in Chinese)

$\mathrm{Xu}$ Y Q, 2003. Evaluation of groundwater level drawdown driving forces in the Hebei Plain to the south of Beijing and Tianjin. Progress in Geography, 22(5): 490-498. (in Chinese)

Yan H M, 2007. Spatial pattern and regional characteristic of cropping system in China based on time-series satellite data [D]. Beijing: Chinese Academy of Sciences. (in Chinese)

Yan H M, Cao M K, Liu J Y et al., 2005b. Characterizing spatial patterns of multiple cropping system in China from multi-temporal remote sensing images. Transactions of the Chinese Society of Agricultural Engineering, 21(4): 85-90.

Yan H M, Ji Y Z, Liu J Y et al., 2016. Potential promoted productivity and spatial patterns of medium- and low-yield cropland land in China. Journal of Geographical Sciences, 26(3): 259-271.

Yan H M, Liu J Y, Cao M K, 2005a. Remote sensed multiple cropping index variations in China during 1981-2000. Acta Geographica Sinica, 60(4): 559-566. (in Chinese)

Yan H M, Xiao X M, Huang H Q et al., 2014. Multiple cropping intensity in China derived from agro-meteorological observations and MODIS data. Chinese Geographical Science, 24(2): 205-219.

Zhang H J, 2014. Implementing well the grain direct subsidy policy and ensuring national food security. Shanxi Science \& Technology, 29: 1-3, 12. (in Chinese)

Zhang J B, Lin X G, Li H, 2011b. A new generation of controlling technology for the medium and low-yield fields and its potential in large-area balanced grain production increase. Bulletin of Chinese Academy of Sciences, 4 : 375-382. (in Chinese)

Zhang X L, Kong X B, 2014. Cropland sustainable use impacted by groundwater depletion in China's $\mathrm{HHH}$ Plains. China Land Sciences, 28(5): 90-96. (in Chinese)

Zhang Z G, 2011. Spatial-temporal characteristics of multiple cropping index and relationship between multiple cropping index and grain yield in Henan province. Hubei Agricultural Sciences, 50(17): 3653-3656. (in Chinese)

Zhang Z G, Li L, 2011a. Temporal variation and prediction of multiple cropping index in Henan Province. Research of Soil \& Water Conservation, 18(4): 241-243, 253. (in Chinese)

Zhao Q, Chen S G, Ye X H, 2009. Practice and reflection on high-standard farmland construction. Agricultural Development \& Equipments, 3: 18-21. (in Chinese)

Zhou J, Jia L, Menenti M. 2015. Reconstruction of global MODIS NDVI time series: Performance of harmonic analysis of time series (HANTS). Remote Sensing of Environment, 163(15): 217-228.

Zhu H Y, Li X B, Xin L J, 2007. Intensity change in cultivated land use in China and its policy implications. Journal of Natural Resources, 22(6): 907-915. (in Chinese)

Zuo L J, Dong T T, Wang X et al., 2009. Multiple cropping index of northern China based on MODIS/EVI. Transactions of the Chinese Society of Agricultural Engineering, 25(8): 141-146. (in Chinese)

Zuo L J, Wang X, Zhang Z X et al., 2014. Developing grain production policy in terms of multiple cropping systems in China. Land Use Policy, 40: 140-146. 